\title{
Synthesis and Characterization of Quinoxaline-Based Thiophene Copolymers as Photoactive Layers in Organic Photovoltaic Cells
}

\author{
Yoon-Suk Choi, Woo-hyung Lee, Jae-Ryoung Kim, ${ }^{\dagger}$ Sang-Kyu Lee, ${ }^{\dagger}$ Won-Suk Shin, ${ }^{\dagger}$ Sang-Jin Moon, ${ }^{\dagger}$ \\ Jong-Wook Park, and In-Nam Kang* \\ Department of Chemistry, The Catholic University of Korea, Bucheon, Gyeonggi-do 420-743, Korea \\ ${ }^{*}$ E-mail: inamkang@catholic.ac.kr \\ ${ }^{\dagger}$ Energy Materials Research Division, Korea Research Institute of Chemical Technology, P.O. BOX 107, \\ Yuseong, Daejeon 305-600, Korea \\ Received October 5, 2010, Accepted November 23, 2010
}

\begin{abstract}
A series of new quinoxaline-based thiophene copolymers (PQx2T, PQx4T, and PQx6T) was synthesized via Yamamoto and Stille coupling reactions. The $M_{\mathrm{w}} \mathrm{S}$ of PQx2T, PQx4T, and PQx6T were found to be 20,000, 12,000, and 29,000, with polydispersity indices of 2.0, 1.2, and 1.1, respectively. The UV-visible absorption spectra of the polymers showed two distinct absorption peaks in the ranges $350-460 \mathrm{~nm}$ and $560-600 \mathrm{~nm}$, which arose from the $\pi-\pi^{*}$ transition of oligothiophene units and intramolecular charge transfer (ICT) between a quinoxaline acceptor and thiophene donor. The HOMO levels of the polymer ranged from -5.37 to $-5.17 \mathrm{eV}$ and the LUMO levels ranged from -3.67 to $-3.45 \mathrm{eV}$. The electrochemical bandgaps of PQx2T, PQx4T, and PQx6T were 1.70, 1.71, and $1.72 \mathrm{eV}$, respectively, thus yielding low bandgap behavior. PQx2T, PQx4T, and PQx6T had open circuit voltages of $0.58,0.42$, and $0.47 \mathrm{~V}$, and short circuit current densities of 2.9, 5.29 and $9.05 \mathrm{~mA} / \mathrm{cm}^{2}$, respectively, when $\mathrm{PC}_{71} \mathrm{BM}$ was used as an acceptor. For the solar cells with PQx2T-PQx6T:PC 71 BM (1:3) blends, an increase in performance was observed in going from $\mathrm{PQx} 2 \mathrm{~T}$ to PQx6T. The power conversion efficiencies of PQx2T, PQx4T, and PQx6T devices were found to be $0.69 \%, 0.73 \%$, and $1.80 \%$ under AM $1.5 \mathrm{G}\left(100 \mathrm{~mW} / \mathrm{cm}^{2}\right)$ illumination.
\end{abstract}

Key Words: Organic solar cell, Quinoxaline, Oligothiophene, Thin film transistor, Conjugated polymers

\section{Introduction}

Organic electronic devices based on solution-processable organic semiconductors have been increasingly investigated for use in low-cost memory devices, large-area display devices, and flexible electronic devices such as organic thin film transistors (OTFTs) ${ }^{1-3}$ and organic photovoltaic cells (OPVs). ${ }^{4-7}$ In particular, organic photovoltaic cells have attracted much scientific and industrial interest because of their significant advantages, including their simplicity, low production cost, and applications in renewable solar energy. The recent development of novel polymers and processing techniques has resulted in dramatic improvements in the performance of OPVs, and an efficiency of more than $7 \%$ has been reported. ${ }^{8}$ In the common device structure of OPVs, a blend of an electron-donor (p-type conjugated polymer) and electron-acceptor $\left([6,6]\right.$-phenyl- $\mathrm{C}_{61}{ }^{-}$ butyric acid methyl ester, PCBM) is used as a photoactive layer between two electrodes. ${ }^{9-13}$ This well known structure, commonly referred to as a bulk heterojunction (BHJ) device, has been the most widely used configuration for polymer-based solar cells. Conjugated copolymers with alternating donoracceptor units have been extensively used to obtain low-bandgap donor polymers, because the intramolecular charge transfer (ICT) mechanism within the donor-acceptor structure allows extension of the conjugation length to achieve high-performance organic photovoltaic cells (OPVs). ${ }^{14-17}$ Low bandgap polymers are expected to be promising materials for the development of OPVs because of the improved absorption of the solar photon flux. Within the class of low-bandgap polymers, quinoxaline-based polymers are widely used as active materials for OPVs. ${ }^{18-21}$ The quinoxaline moiety, which contains electronwithdrawing nitrogen atoms, is highly electron deficient and thus serves as an efficient electron acceptor; therefore, it easily forms ICT complexes with other donor components. ${ }^{22}$

Here, we report the synthesis and characterization of a new class of quinoxaline-based thiophene copolymers, specifically poly[2,3-bis-((4-octyloxy)-phenyl)-5,8-dithien-2-yl-quinoxaline] (PQx2T), poly[2,3-bis-((4-octyloxy)-phenyl)-5,8-dithien2-yl-quinoxaline-alt-2,2'-bithiophene] (PQx4T), and poly[2,3bis-((4-octyloxy)-phenyl)-5,8-bis(5'-bromo-4'-hexyl-2,2'bithiophene-5-yl-quinoxaline)-alt-2,2'-bithiophene] (PQx6T), that function as photoactive semiconductors in OPVs. To increase the solubility of the polymers, an easily accessible octyloxyphenyl ring was incorporated in the quinoxaline units. The ICT behavior was studied by changing the number of electronrich thiophene rings with the electron-accepting quinoxaline unit in the polymer backbones. Bulk heterojunction-type devices with $\mathrm{PC}_{71} \mathrm{BM}$ (3'H-cyclopropa[8,25][5,6]fullerene- $\mathrm{C}_{70^{-}}$ $\mathrm{D}_{5 \mathrm{~h}}(6)-3$ '-butanoic acid, 3'-phenyl-, methyl ester) acceptors were fabricated to investigate the photovoltaic properties of the polymers. Furthermore, the influence of structural variation on fieldeffect mobility in OTFTs was investigated to understand charge transport in the solar cell devices. Devices using PQx6T and $\mathrm{PC}_{71} \mathrm{BM}$ blends as the active layer exhibited $1.80 \%$ power conversion efficiency.

\section{Experimental Section}

Synthesis of Monomers. 4,7-Dibromo-2,1,3-benzothiadiazole (1), ${ }^{23} 3,6$-dibromo-1,2-phenylenediamine (2), ${ }^{24} 1,4$-dime- 
thylpiperazine-2,3-dione (3), ${ }^{25}$ 1-bromo-4-(octyloxy) benzene (4), ${ }^{26} 4,4$ '-bis(2-octyloxy)benzil (5), ${ }^{25}$ 5,8-Dibromo-2,3-bis-(4octyloxyphenyl)quinoxaline (6), ${ }^{27}$ 2,3-Bis(4-octyloxyphenyl)5,8-dithien-2-ly quinoxaline (7), ${ }^{27}$ 2,3-bis(4-octyloxyphenyl)5,8 -bis(5'-bromo-dithien-2-ly)quinoxaline (8), ${ }^{27}$ and 5,5'-bis (trimethylstannyl)-2,2'-bithiophene ${ }^{28}$ were prepared with previously described methods.

2,3-Bis(4-octyloxyphenyl)-5,8-bis(4'-hexyl-2,2'-bithiophene-5-ly)quinoxaline (9): To a stirred mixture of compound 8 (2.0 g, $2.32 \mathrm{mmol})$, 4,4,5,5-tetramethyl-2-(4-octyl-thiophene2-ly)-[1,3,2]-dioxaborolane (1.5 g, $5.11 \mathrm{mmol})$, tetrakis(triphenylphosphine) palladium $(0)(0.13 \mathrm{~g}, 0.12 \mathrm{mmol})$, and Aliquat 336 ( 2 drops) in $30 \mathrm{~mL}$ of toluene and $25 \mathrm{~mL}$ of $2 \mathrm{M}$ aqueous sodium carbonate solution was added. The solution was refluxed with vigorous stirring for $20 \mathrm{~h}$ under a nitrogen atmosphere. The mixture was poured into water $(100 \mathrm{~mL})$ and extracted with $\mathrm{CHCl}_{3}$. The extract was then successively washed with water and brine. After drying over anhydrous $\mathrm{MgSO}_{4}$, the solvent was evaporated and the residue was purified by column chromatography on silica gel with $n$-hexane: toluene $(2: 1)$ as eluent to give compound 9 as a red solid $(1.6 \mathrm{~g}, 64 \%)$. ${ }^{1} \mathrm{H} \mathrm{NMR}\left(\mathrm{CDCl}_{3}\right.$, $300 \mathrm{MHz}, \mathrm{ppm})$ 8,04 (s, 2H), 7.77 (d, 4H) 7.75 (d, 2H) 7.20 (d, 2H) $6.93(\mathrm{~d}, 4 \mathrm{H}) 6.84(\mathrm{~s}, 2 \mathrm{H}) 4.00(\mathrm{t}, 4 \mathrm{H}) 2.62(\mathrm{t}, 4 \mathrm{H}) 1.81(\mathrm{~m}$, 4H) $1.65(\mathrm{~m}, 4 \mathrm{H}) 1.48-1.30(\mathrm{~m}, 32 \mathrm{H}) 0.89(\mathrm{t}, 12 \mathrm{H}) .{ }^{13} \mathrm{C} \mathrm{NMR}$ $\left(\mathrm{CDCl}_{3}, 80 \mathrm{MHz}, \mathrm{ppm}\right) 160.03,150.99,144.13,140.63,137.67$, 137.21, 136.61, 132.04, 131.01, 130.31, 126.60, 125.58, 124.66, $122.80,118.96,114.08,48.06,31.86,31.75,30.61,30.40,29.45$, 29.34, 29.29, 29.10, 26.13, 22.70, 14.14 Anal. Calcd. for $\mathrm{C}_{64} \mathrm{H}_{78}-$ $\mathrm{N}_{2} \mathrm{O}_{2} \mathrm{~S}_{4}$ : C, 74.23; H, 7.59; N, 2.71; S, 12.39. Found: C, 74.34; $\mathrm{H}, 7.58 ; \mathrm{N}, 2.71 ; \mathrm{S}, 12.38$.

2,3-Bis(4-octyloxyphenyl)-5,8-bis(5'-bromo-4'-hexyl-2,2'bithiophene-5-ly)quinoxaline (10): To a solution of compound $9(0.81 \mathrm{~g}, 0.78 \mathrm{mmol})$ in a $\mathrm{CHCl}_{3}(10 \mathrm{~mL})$ was cooled to $0{ }^{\circ} \mathrm{C}$ with an ice-water bath. And then NBS $(0.27 \mathrm{~g}, 1.57 \mathrm{mmol})$ was added. After the reaction was finished, the product was extracted with $\mathrm{CHCl}_{3}$. The organic layer was dried over anhydrous $\mathrm{MgSO}_{4}$ and the solvent removed by rotary evaporation. The crude product was purified by crystallization with $\mathrm{MeOH}$ to yield compound 10 as a red solid $(0.9 \mathrm{~g}, 97 \%)$. ${ }^{1} \mathrm{H} \mathrm{NMR}\left(\mathrm{CDCl}_{3}\right.$, $300 \mathrm{MHz}, \mathrm{ppm}) 7.95$ (s, 2H), $7.71(\mathrm{~d}, 4 \mathrm{H}), 7.66(\mathrm{~d}, 2 \mathrm{H}), 7.10$ (d, $2 \mathrm{H}), 6.92(\mathrm{~s}, 2 \mathrm{H}), 6.89(\mathrm{~d}, 4 \mathrm{H}), 4.00(\mathrm{t}, 4 \mathrm{H}), 2.56(\mathrm{t}, 4 \mathrm{H}), 1.80$ $(\mathrm{m}, 4 \mathrm{H}), 1.62(\mathrm{~m}, 4 \mathrm{H}), 1.50-1.30(\mathrm{~m}, 32 \mathrm{H}), 0,89(\mathrm{t}, 12 \mathrm{H}){ }^{13} \mathrm{C}$ $\mathrm{NMR}\left(\mathrm{CDCl}_{3}, 80 \mathrm{MHz}, \mathrm{ppm}\right) 160.08,151.00,142.93,139.60$, $137.47,136.45,132.01,130.84,126.42,125.41,123.87,122.83$, $114.03,68.08,31.86,31.66,29.65,29.45,29.34,29.29,29.01$, 26.13, 22.69, 22.67, 14.13. Anal. Calcd. for $\mathrm{C}_{64} \mathrm{H}_{76} \mathrm{Br}_{2} \mathrm{~N}_{2} \mathrm{O}_{2} \mathrm{~S}_{4}$ : C, 64.41; H, 6.42; N, 2.35; S, 10.75. Found: C, 64.40; H, 6.51; N, 2.32; S, 10.73 .

Poly[2,3-bis(4-octyloxyphenyl)-5,8-dithien-2-ly-quinoxaline], PQx2T: The $100 \mathrm{~mL}$ Schlenk flask containing anhydrous DMF (3.7 mL), bis(1,5-cyclooctadienyl) nickel(0) (0.96 g, 3.49 mmol), 2,2'-dipyridyl (0.54 g, $3.49 \mathrm{mmol})$ and 1,5-cyclooctadiene $(0.42 \mathrm{~mL}, 3.49 \mathrm{mmol})$ was kept under nitrogen atmosphere at $78{ }^{\circ} \mathrm{C}$ for $15 \mathrm{~min}$. Compound $8(1 \mathrm{~g}, 1.16 \mathrm{mmol})$ dissolved in anhydrous toluene $(12 \mathrm{~mL})$ was added to the reaction mixture. The polymerization was maintained at $78^{\circ} \mathrm{C}$ for $36 \mathrm{~h}$. When the reaction had finished, the reaction mixture was precipitated from an equi-volume mixture of $\mathrm{HCl}$, methanol and acetone. The polymer was dissolved in small amount of toluene and then precipitated in methanol. The resulting polymer was further purified by Soxhlet extraction using methanol and then dried in vacuum. The polymer yield was $50 \%(0.5 \mathrm{~g})$ after purification. Anal. Calcd. for $\left(\mathrm{C}_{44} \mathrm{H}_{50} \mathrm{~N}_{2} \mathrm{O}_{2} \mathrm{~S}_{2}\right)_{\mathrm{n}}$ : C, 75.17; H, 7.17; N, 3.98; S, 9.12. Found: C, 72.44; H, 6.87; N, 3.74; S, 8.88.

Poly[2,3-bis(4-octyloxyphenyl)-5,8-dithien-2-ly-quinoxaline-alt-2,2'-bithiophene], PQx4T: A $100 \mathrm{~mL}$ Schlenk flask containing anhydrous chlorobenzene $(10 \mathrm{~mL})$, compound 8 (0.35 g, $0.406 \mathrm{mmol}), 5,5$ '-bis(trimethylstannyl)-2,2'-bithiophene $(0.2 \mathrm{~g}, 0.406 \mathrm{mmol})$, tris(dibenzylideneacetone)dipalla$\operatorname{dium}(0)(0.036 \mathrm{~g}, 0.0406 \mathrm{mmol})$, and tricyclohexyl phosphine $(0.023 \mathrm{~g}, 0.0812 \mathrm{mmol})$ was kept under nitrogen atmosphere at $130{ }^{\circ} \mathrm{C}$ for $72 \mathrm{~h}$. When the reaction had finished, the reaction mixture was precipitated from the $10 \mathrm{~mL}$ of $\mathrm{HCl}$ and $150 \mathrm{~mL}$ of methanol. The polymer was dissolved in small amount of toluene and precipitated in methanol. The resulting polymer was further purified by Soxhlet extraction using methanol and then dried in vacuum to give dark-green solid $(0.26 \mathrm{~g}, 80 \%)$. Anal. Calcd. for $\left(\mathrm{C}_{52} \mathrm{H}_{54} \mathrm{~N}_{2} \mathrm{O}_{2} \mathrm{~S}_{4}\right)_{\mathrm{n}}$ : C, 72.02; H, 6.28; N, 3.23; S, 14.79. Found: C, 69.98; H, 6.42; N, 2.80; S, 13.64.

Poly[2,3-bis(4-octyloxyphenyl)-5,8-bis(5'-bromo-4'-hexyl2,2'-bithiophene-5-ly-quinoxaline)-alt-2,2'-bithiophene], PQx6T: PQx6T was synthesized using the same Stille coupling procedure as for PQx4T with compound $9(0.36 \mathrm{~g}, 0.302$ mmol), 5,5'-bis(trimethylstannyl)-2,2'-bithiophene (0.15 g, $0.302 \mathrm{mmol})$, tris(dibenzylideneacetone)dipalladium $(0)(0.027$ g, $0.0302 \mathrm{mmol})$, tri-cyclohexylphosphine $(0.017 \mathrm{~g}, 0.0604$ $\mathrm{mmol})$, and chlorobenzene $(9.0 \mathrm{~mL})$. Yield $(0.30 \mathrm{~g}, 83 \%$, darkish green color). Anal. Calcd. for $\left(\mathrm{C}_{72} \mathrm{H}_{82} \mathrm{~N}_{2} \mathrm{O}_{2} \mathrm{~S}_{6}\right)_{\mathrm{n}}$ : C, 72.07; H, 6.89; N, 2.33; O, 2.67; S, 16.03. Found: C, 71.49; H, 7.00; N, 2.16; S, 15.84 .

Instrumentation. ${ }^{1} \mathrm{H}$ and ${ }^{13} \mathrm{C} \mathrm{NMR}$ spectra were recorded on a Bruker AVANCE 400 spectrometer, with tetramethyl silane as an internal reference. The optical absorption spectra were measured on a Shimadzu UV-3100 UV-VIS-NIR spectrometer. The number- and weight-averaged molecular weights of polymers were determined by gel permeation chromatography (GPC) on a Viscotek T60A instrument, using tetrahydrofuran (THF) as eluent and polystyrene as a standard. Thermal gravimetric analysis (TGA) was obtained using a TA Q100 instrument operated under a nitrogen atmosphere. Cyclic voltammetry was performed on an AUTOLAB/PG-STAT12 model system with a three-electrode cell in an acetonitrile solution of $\mathrm{Bu}_{4} \mathrm{NBF}_{4}$ $(0.10 \mathrm{M})$ at a scan rate of $50 \mathrm{mV} / \mathrm{s}$. Polymer film coatings on $\mathrm{Pt}$ wire electrodes were formed by dipping electrodes into a solution of the appropriate polymer. Atomic force microscopy (AFM) measurements were obtained in tapping-mode using a Multimode IIIa Digital Instrument AFM. Electrical characteristics of the TFTs were measured under ambient conditions using both Keithley 2400 and 236 source/measure units. All measurements were obtained with channel lengths (L) of $100 \mu \mathrm{m}$ and channel widths (W) of $1000 \mu \mathrm{m}$. Field-effect mobilities were extracted in the saturation regime from the slope of the source-drain current.

Fabrication of the Organic Thin Film Transistor Devices. Thin-film transistors were fabricated on silicon wafers using a top contact geometry (channel length $L=100 \mu \mathrm{m}$, width $W=$ 
$1000 \mu \mathrm{m})$ under ambient conditions without taking special precautions to exclude air, moisture, or light. A heavily $n$-doped silicon wafer with a $300 \mathrm{~nm}$ thermal silicon dioxide $\left(\mathrm{SiO}_{2}\right)$ layer was used as the substrate/gate electrode, with the top $\mathrm{SiO}_{2}$ layer serving as the gate dielectric. The $\mathrm{SiO}_{2}$ surface of the wafer substrate was first cleaned with piranha solution $\left(\mathrm{H}_{2} \mathrm{O}_{2} / \mathrm{H}_{2} \mathrm{SO}_{4}\right)$ at $130{ }^{\circ} \mathrm{C}$ for $20 \mathrm{~min}$, and the cleaned wafer was immersed in a solution of $1.0 \mathrm{mM}$ octyltrichlorosilane (OTS-8) in toluene at room temperature for $2 \mathrm{~h}$ under nitrogen. The semiconductor layer was spin-coated at $2000 \mathrm{rpm}$ from a $0.5 \mathrm{wt} \%$ chlorobenzene solution, to a thickness of $60 \mathrm{~nm}$. Subsequently, a series of gold source/drain electrode pairs were deposited by vacuum evaporation through a shadow mask. Silicon oxide at the backside of the silicon wafer of the TFT device was removed with HF to provide a conductive gate contact.

Fabrication of the Organic Photovoltaic Device. Composite solutions with the quinoxaline based copolymers and $\mathrm{PC}_{71} \mathrm{BM}$ were prepared using 1,2-dichlorobenzene (DCB). The polymer photovoltaic devices were fabricated with a typical sandwich structure of ITO/PEDOT:PSS/active layer/LiF/Al. The ITOcoated glass substrates were cleaned by a routine cleaning procedure, including sonication in detergent followed by sonication in distilled water, acetone, and 2-propanol. A $45 \mathrm{~nm}$ thick layer of PEDOT:PSS (Baytron P) was spin-coated onto a cleaned ITO substrate after exposing the ITO surface to ozone for $10 \mathrm{~min}$. The PEDOT:PSS layer was baked on a hot plate at $120{ }^{\circ} \mathrm{C}$ for $60 \mathrm{~min}$. The active layer was spin-coated from the pre-dissolved composite solution after filtering through $0.45 \mu \mathrm{m}$ PP syringe filters. The device structure was completed by depositing $0.6 \mathrm{~nm} \mathrm{LiF}$ and then $130 \mathrm{~nm} \mathrm{Al}$ cathode as the top electrode onto the polymer active layer under a $3 \times 10^{-6}$ torr. in a thermal evaporator.

\section{Results and Discussion}

Synthesis and Thermal Properties of the Polymers. The synthetic routes to the monomers are outlined in Scheme 1. The synthetic routes to the polymers PQx2T, PQx4T, and PQx6T are described in Scheme 2. PQx2T was synthesized by a Ni(0)mediated coupling reaction of compound 8. PQx4T and PQx6T were prepared by a Stille coupling reaction of 5,5'-bis(trimethylstannyl)-2,2'-bithiophene and either compound 8 or 10 . The polymer yields were $50-83 \%$ after purification. Elemental analyses of the polymers were in reasonable agreement with the theoretical values. The resulting PQx6T showed good solubility in common organic solvents such as chloroform, chlorobenzene, and toluene because of the long alkyl side chain, but PQx2T and PQx4T exhibited relatively poor solubility compared with PQx6T because of the incorporation of the rigid thiophene units into the polymer backbones. The molecular weights and polydispersity indices of the polymers were determined by gel permeation chromatography using THF as the eluent and polystyrene as the standard. The $M_{\mathrm{w}} \mathrm{S}$ of PQx2T, PQx4T, and PQx6T were found to be 20,000, 12,000, and 29,000, with polydispersity indices of $2.0,1.2$, and 1.1 , respectively. The excellent thermal stabilities of PQx2T, PQx4T, and PQx6T were evident from their TGA profiles, with decomposition temperatures above $350{ }^{\circ} \mathrm{C}$ (Figure 1). The weight losses for PQx2T,
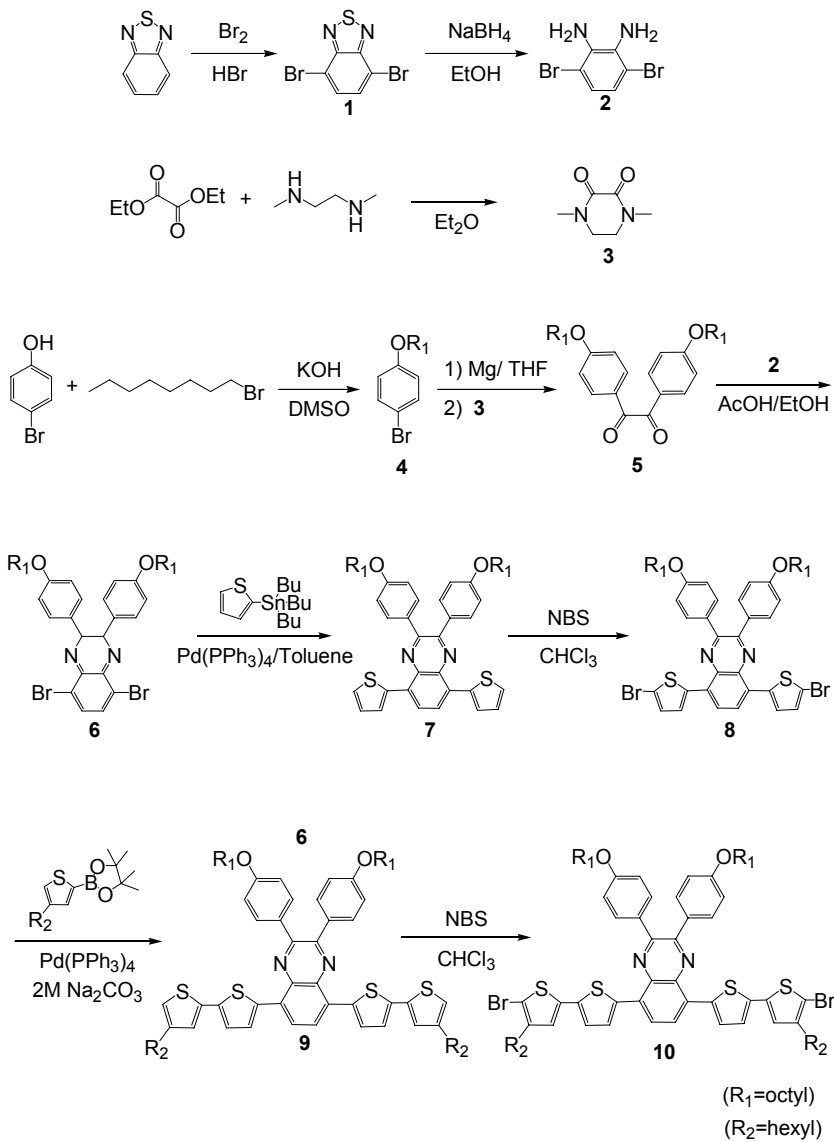

Scheme 1. Synthetic routes for quinoxaline containing monomers

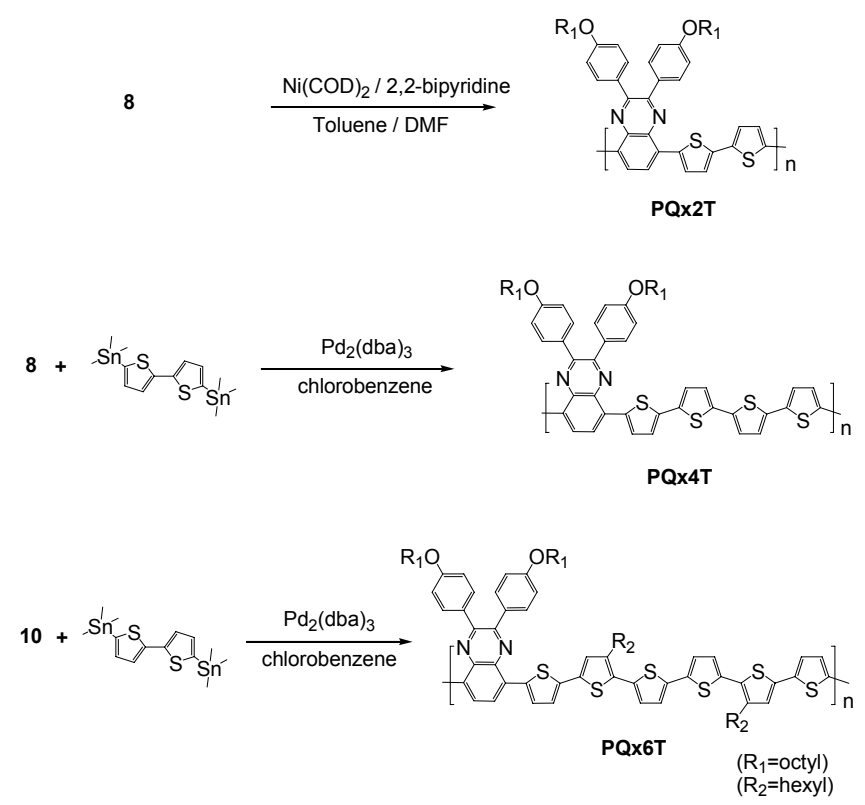

Scheme 2. Synthetic routes for PQx2T, PQx4T, and PQx6T

PQx4T, and PQx6T were $6.9 \%, 2.7 \%$, and $0.9 \%$ at $350{ }^{\circ} \mathrm{C}$, respectively. These results for the synthesized polymers are summarized in Table 1.

Optical and Electrochemical Properties of the Polymers. The 


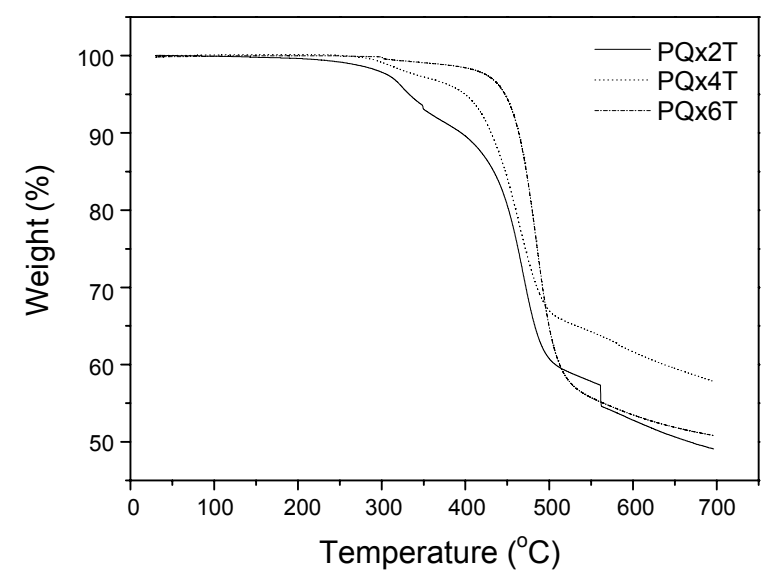

Figure 1. TGA thermograms of the PQx2T, PQx4T, and PQx6T at a heating rate $10{ }^{\circ} \mathrm{C} \mathrm{min}-1$ under an inert atmosphere.

(a)

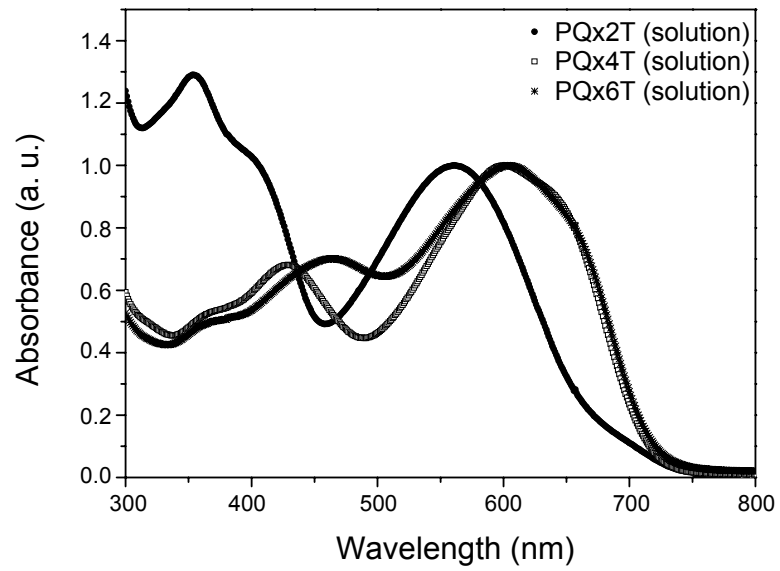

(b)

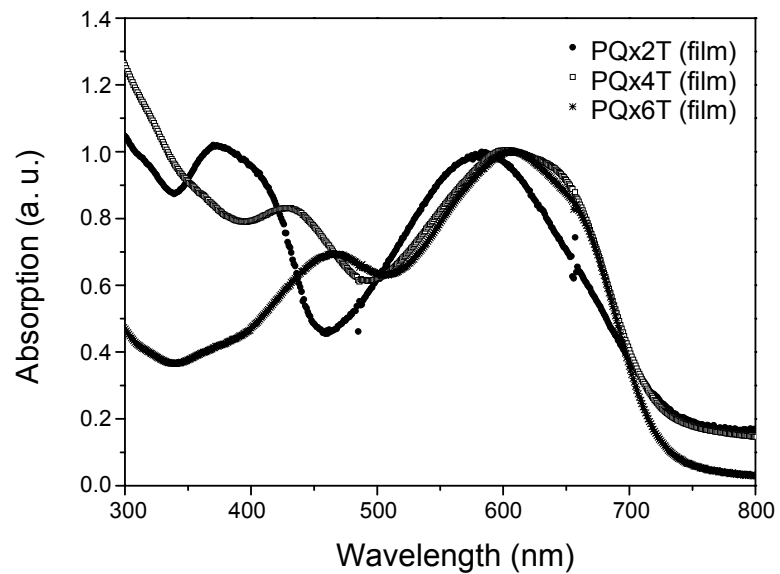

Figure 2. UV-visible spectra of the PQx2T, PQx4T, and PQx6T (a) in chlorobenzene solution and (b) in thin films.

UV-visible absorption spectra of the polymers in chlorobenzene solution and as thin solid films are presented in Table 2 and Figure 2. All polymers showed two distinct absorption peaks in the ranges $350-460 \mathrm{~nm}$ and $560-600 \mathrm{~nm}$, which is a common feature of intramolecular donor-acceptor copolymers. ${ }^{29-31}$ The short wavelength (350 - $460 \mathrm{~nm}$ ) absorption peak originates from a $\pi-\pi^{*}$ transition of the oligothiophene units, while the longer wavelength (560 - $600 \mathrm{~nm})$ absorption peak is due to an
Table 1. Physical properties of the PQx2T, PQx4T, and PQx6T

\begin{tabular}{ccccc}
\hline Polymer & $\mathrm{M}_{\mathrm{n}}(\mathrm{g} / \mathrm{mol})$ & $\mathrm{M}_{\mathrm{w}}(\mathrm{g} / \mathrm{mol})$ & $\mathrm{M}_{\mathrm{w}} / \mathrm{M}_{\mathrm{n}}$ & $\mathrm{T}_{\mathrm{d}}\left({ }^{\circ} \mathrm{C}\right)^{a}$ \\
\hline PQx2T & 9,900 & 20,000 & 2.0 & 332 \\
PQx4T & 10,000 & 12,000 & 1.2 & 399 \\
PQx6T & 26,000 & 29,000 & 1.1 & 447
\end{tabular}

${ }^{a}$ Temperature for $5 \%$ weight loss.

Table 2. UV-visible maximum absorption wavelength $\left(\lambda_{\max }\right)$, bandgap energy $\left(\mathrm{E}_{\mathrm{g}}\right)$, and ionization potential $\left(\mathrm{E}_{\mathrm{HOMO}}\right)$ of the $\mathrm{PQx} 2 \mathrm{~T}, \mathrm{PQx} 4 \mathrm{~T}$, and PQx6T

\begin{tabular}{|c|c|c|c|c|c|c|}
\hline \multirow{2}{*}{ Polymer } & \multicolumn{2}{|c|}{$\lambda_{\max }(\mathrm{nm})$} & \multirow{2}{*}{$\begin{array}{c}\varepsilon \\
(\mathrm{L} / \mathrm{mol} \cdot \mathrm{cm})^{b}\end{array}$} & \multirow{2}{*}{$\begin{array}{c}\mathrm{E}_{\mathrm{g}} \\
(\mathrm{eV})^{c}\end{array}$} & \multirow{2}{*}{$\begin{array}{c}\text { Eномо }_{\text {Ном }} \\
(\mathrm{eV})\end{array}$} & \multirow{2}{*}{$\begin{array}{c}E_{\text {LUMO }} \\
(\mathrm{eV})\end{array}$} \\
\hline & Solution $^{a}$ & Film & & & & \\
\hline PQx & 56 & 58 & & 1. & -5 & -3.67 \\
\hline PQx4T & 601 & 602 & 22000 & 1.71 & -5.21 & -3.50 \\
\hline PQx6T & 603 & 608 & 53000 & 1.72 & -5.17 & -3.45 \\
\hline
\end{tabular}

${ }^{a}$ Measurements preformed in chlorobenzene. ${ }^{b}$ Absorption coefficient of the polymers at $\lambda_{\max }$ in chlorobenzene. ${ }^{c}$ Electrochemical band gap. $\mathrm{E}_{\mathrm{g}}$ is defined as the difference between $\mathrm{E}_{\text {Hомо }}$ and $\mathrm{E}_{\mathrm{LUMO}}$.

ICT $\pi-\pi^{*}$ transition between the quinoxaline acceptor and the oligothiophene donor. ${ }^{32}$ The short wavelength absorption peaks of PQx2T, PQx4T, and PQx6T in chlorobenzene solution were observed at 353,428 , and $465 \mathrm{~nm}$, respectively, while those of thin films were observed at 370, 430, and $465 \mathrm{~nm}$, respectively. It was noted that the short wavelength absorption peaks of PQx4T and PQx6T were hugely red shifted (by about 60 - $90 \mathrm{~nm}$ ) compared with PQx2T in thin solid films. This red shift can be attributed to an elongation of the effective conjugation length upon increasing the number of thiophene rings in the polymer backbone, which would enhance intra/intermolecular orbital overlap, resulting in a red shift in absorption. The long wavelength absorption peaks of PQx2T, PQx4T, and PQx6T in chlorobenzene solution were observed at 561, 601, and $603 \mathrm{~nm}$, respectively, while those of the thin films were observed at 583, 602 , and $608 \mathrm{~nm}$, respectively. To gain insight into the performance of solar cell devices based on these polymers, we determined the energy levels of their highest occupied molecular orbital (HOMO) and lowest unoccupied molecular orbital (LUMO) using cyclic voltammetry (CV) (Figure 3, Table 2). The redox behavior of the polymer thin films was estimated from CV measurements of dip-coated thin films on indium-tin oxide (ITO)-coated glass, which formed the working electrode. A platinum rod was used as the counter electrode, and $\mathrm{Ag} / \mathrm{Ag}^{+}$ as the reference electrode in acetonitrile with a $0.1 \mathrm{Mn} n-\mathrm{Bu}_{4} \mathrm{NPF}_{6}$ supporting electrolyte solution at a scan rate of $50 \mathrm{mV} \mathrm{s}^{-1}$. The HOMO levels of PQx2T, PQx4T, and PQx6T were estimated to be $-5.37,-5.21$, and $-5.17 \mathrm{eV}$, respectively, and those of the LUMO levels were estimated to be $-3.67,-3.50$, and $-3.45 \mathrm{eV}$, respectively. The electrochemical bandgaps, which are defined as the difference between the HOMO and LUMO levels, of PQx2T, PQx4T, and PQx6T were 1.70, 1.71, and $1.72 \mathrm{eV}$, respectively, resulting in a low bandgap. These results indicate that the HOMO and LUMO levels of the resulting polymers are shifted toward the vacuum level upon increasing the number of thiophene rings in the polymer backbones, which is due to 


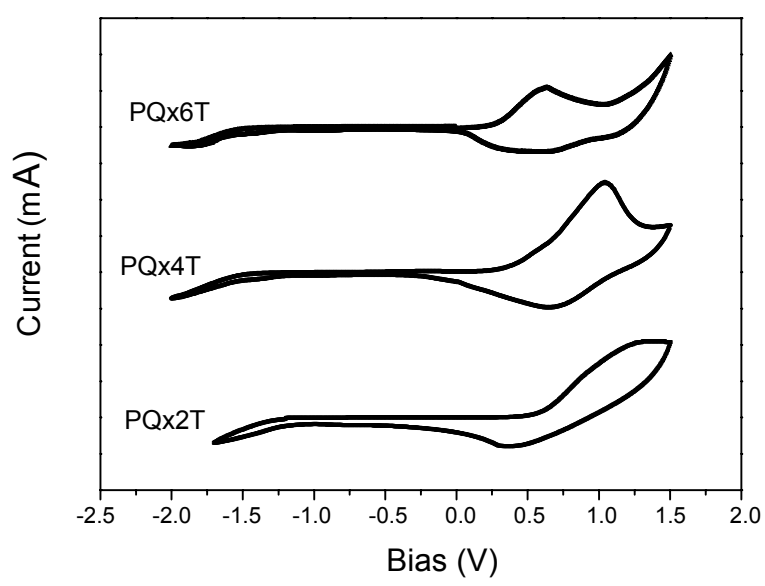

Figure 3. Cyclic voltammograms of the three polymer films on ITO glass at a scanning rate of $50 \mathrm{mV} \mathrm{s}^{-1}$ in acetonitrile containing $0.1 \mathrm{M}$ $n-\mathrm{Bu}_{4} \mathrm{NBF}_{4}$.

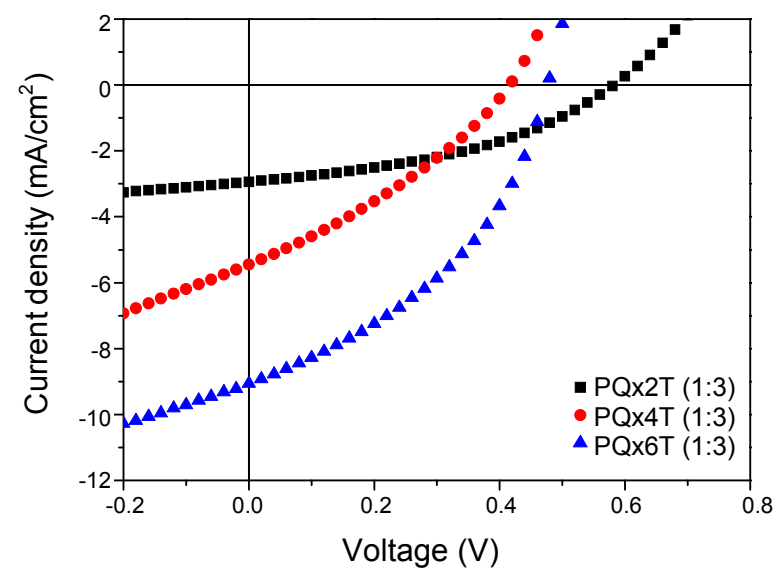

Figure 4. $J-V$ characteristics of photovoltaic cells prepared from polymers: $\mathrm{PC}_{71} \mathrm{BM}(1: 3)$ blend active materials under an illumination of AM $1.5 \mathrm{G}, 100 \mathrm{~mW} / \mathrm{cm}^{2}$.

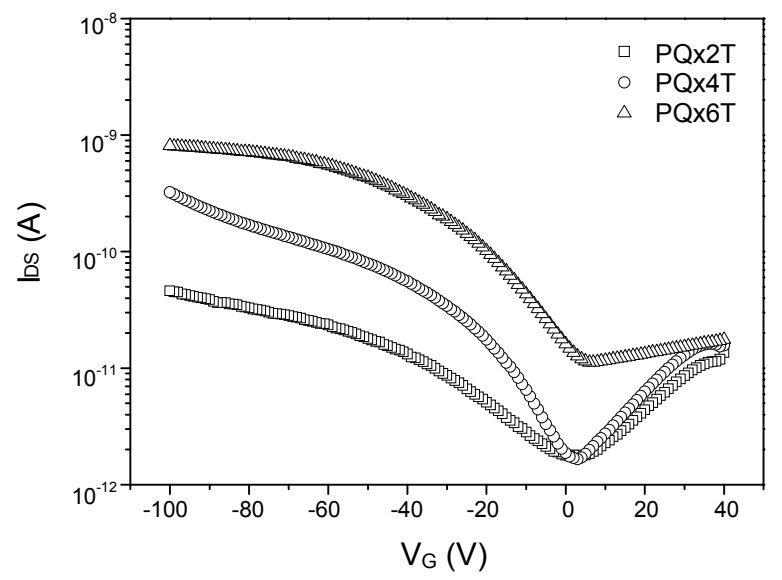

Figure 5. (a) Transfer characteristics of the polymer TFT devices with an OTS-modified surface and annealed at $100^{\circ} \mathrm{C}$, where $\mathrm{V}_{\mathrm{DS}}=-60 \mathrm{~V}$. (b) Output characteristics of PQx6T based TFT devices.

the high HOMO level of the oligothiophene groups.

Organic Photovoltaic (OPV) Characteristics of the Polymer Thin Film. Bulk heterojunction solar cells were fabricated with
Table 3. Photovoltaic properties of the polymer: $\mathrm{PC}_{71} \mathrm{BM}$ devices

\begin{tabular}{cccccc}
\hline $\begin{array}{c}\text { Polymer:PCBM } \\
\text { ratio (wt.) }\end{array}$ & $\begin{array}{c}\text { Film } \\
\text { Thickness (nm) }\end{array}$ & $\begin{array}{c}\mathrm{J}_{\mathrm{SC}} \\
\left(\mathrm{mA} / \mathrm{cm}^{2}\right)\end{array}$ & FF & $\begin{array}{c}\mathrm{V}_{\mathrm{OC}} \\
(\mathrm{V})\end{array}$ & $\begin{array}{c}\text { PCE } \\
(\%)\end{array}$ \\
\hline PQx2T (1:3) & 69 & 2.90 & 0.41 & 0.58 & 0.69 \\
PQx4T (1:3) & 67 & 5.29 & 0.33 & 0.42 & 0.73 \\
PQx6T (1:3) & 65 & 9.05 & 0.42 & 0.47 & 1.80 \\
\hline
\end{tabular}

a sandwich structure of ITO/PEDOT:PSS $(50 \mathrm{~nm}) /$ polymer: $\mathrm{PC}_{71} \mathrm{BM} / \mathrm{LiF}(0.6 \mathrm{~nm}) / \mathrm{Al}(130 \mathrm{~nm})$. After deposition of the PEDOT:PSS layer on the top of the anode (ITO), the active materials were deposited via spin coating from a 1,2-dichlorobenzene solution of polymer and $\mathrm{PC}_{71} \mathrm{BM}$. The resulting films were dried under vacuum at room temperature for $4 \mathrm{~h}$, and then annealed at $90{ }^{\circ} \mathrm{C}$ for $10 \mathrm{~min}$ to remove a solvent. In the bulk heterojunction solar cells, the polymers were used as an electron donor and $\mathrm{PC}_{71} \mathrm{BM}$ was used as an electron acceptor. The $J-V$ characteristics of the polymer solar cells prepared from the polymer (PQx2T, $\mathrm{PQx} 4 \mathrm{~T}$, and $\mathrm{PQx} 6 \mathrm{~T}$ ): $\mathrm{PC}_{71} \mathrm{BM}$ blend materials are shown in Figure 4 . The open circuit voltage $\left(V_{\mathrm{OC}}\right)$, short circuit current density $\left(J_{\mathrm{SC}}\right)$, fill factor $(\mathrm{FF})$, and power conversion efficiency (PCE) of these devices are summarized in Table 3. For these devices based on the PQx2T-PQx6T:PC ${ }_{71} \mathrm{BM}(1: 3)$ blend materials, an increase in performance was observed in going from PQx2T to PQx6T. The PCEs of the PQx2T, PQx4T, and PQx6T devices were found to be $0.69 \%, 0.73 \%$, and $1.80 \%$, respectively. As shown in Table 3, the PQx2T, PQx4T, and PQx6T devices exhibited $J_{\mathrm{SC}}$ values of $2.9,5.29$, and $9.05 \mathrm{~mA} /$ $\mathrm{cm}^{2}$, when the polymer $v s$. PCBM blend ratio was $1: 3$. The $J_{\mathrm{SC}}$ of these polymers was found to increase as the number of thiophene rings in the polymer backbone increased. Because the mobility of the donor polymer is an important parameter that can affect the $J_{\mathrm{SC}}$ values, the field-effect hole mobility was measured using an OTFT device with a top contact configuration built on an $n$-doped silicon wafer. The saturation mobilities of PQx2T, PQx4T, and PQx6T were found to be $9.0 \times 10^{-8}, 5.0 \times$ $10^{-7}$, and $2.4 \times 10^{-5} \mathrm{~cm}^{2} \mathrm{~V}^{-1} \mathrm{~s}^{-1}$, respectively (Figure 5). The $J_{\mathrm{SC}}$ should generally increase with the increasing hole mobility of the electron-donor polymers, which enhances charge transport in the bulk heterojunctions. Therefore, the above results indicate that increasing the number of thiophene rings in the polymer backbone enhances the hole mobility in the blend films, and thus improves the PCE. In addition, the $V_{\mathrm{OCS}}$, which are related to the difference between the HOMO level of the donor polymer and the LUMO level of the acceptor (PCBM), of the PQx2T$\mathrm{PQx} 6 \mathrm{~T}: \mathrm{PC}_{71} \mathrm{BM}(1: 3)$ devices were found to be $0.58,0.42$, and $0.47 \mathrm{~V}$, respectively. With the same electron acceptor $\left(\mathrm{PC}_{71} \mathrm{BM}\right.$ in this study), electron donors with lower HOMO give higher $V_{\mathrm{OC}}$ values, however, the trend of $V_{\mathrm{OC}}$ for PQx $4 \mathrm{~T}$ does not seem to fit to the electrochemical potentials. This result can be understood in terms of the film morphology of the blended film. Low solubility has an impact on the film mechanical properties, the interface resistance, and the morphology, resulting in a low open-circuit voltage and a low fill factor. ${ }^{29}$ To investigate the surface morphology of the blend films, we examined AFM images of PQx2T-PQx6T:PC ${ }_{71} \mathrm{BM}$ (1:3) films spin-coated from their corresponding 1,2-dichlorobenzene solutions, identical 

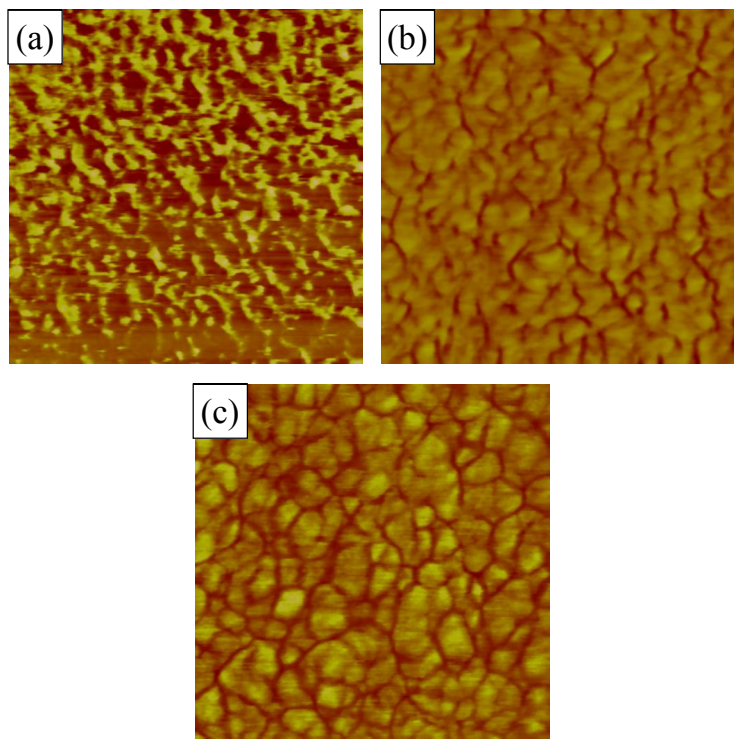

Figure 6. AFM tapping mode phase images of thin films cast from (a) PQx2T:PC ${ }_{71} \mathrm{BM}$ (1:3), (b) PQx4T:PC $71 \mathrm{BM}$ (1:3), and (c) PQx6T: $\mathrm{PC}_{71} \mathrm{BM}(1: 3)$. Scan size is $500 \mathrm{~nm} \times 500 \mathrm{~nm}$.

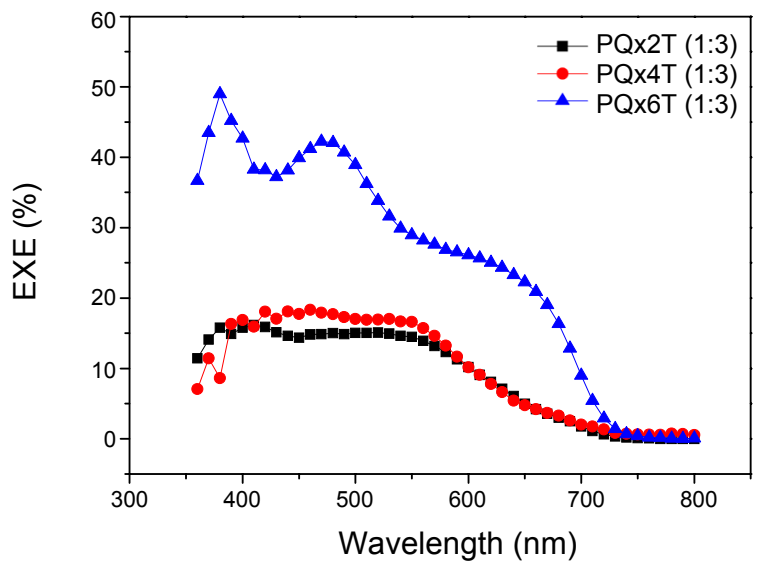

Figure 7. External quantum efficiencies of copolymer/ $\mathrm{PC}_{71} \mathrm{BM}$ solar cells.

to the procedure used to fabricate the active layers of the solar cell devices. We observed coarse phase separation in the images of these polymer blends. Coarse phase separation was evident in the images of the PQx6T:PC ${ }_{71} \mathrm{BM}(1: 3)$ films, whereas the PQx2T-PQx4T:PC 71 BM (1:3) films showed a smoother and more homogeneous surface. The root-mean-square (RMS) roughness of the PQx2T, PQx4T, and PQx6T blends was 0.56, 1.32 , and $1.28 \mathrm{~nm}$, respectively. These results suggest that the differences in PCE for PQx2T-PQx6T:PC ${ }_{71} \mathrm{BM}$ (1:3) devices may be the result of a decrease in the interfacial area and ability for hole transportation of the donor polymers. The external quantum efficiency (EQE), which is used to evaluate the photoresponse of the fabricated solar cells as a function of wavelength, is shown in Figure 7. All of the devices show high photoconversion efficiency over the wavelength range $400-700 \mathrm{~nm}$, which covers most of the visible wavelength range. The PQx6T: $\mathrm{PC}_{71} \mathrm{BM}$ device shows relatively high photoconversion efficiency with significantly increased absorption in the range from
350 to $600 \mathrm{~nm}$, with EQE values above $30 \%$ and a maximum EQE of almost $40 \%$ at around $480 \mathrm{~nm}$. In particular, the PQx6T: $\mathrm{PC}_{71} \mathrm{BM}$ device yielded an EQE plot that was similar to the absorption spectrum of $\mathrm{PQx} 6 \mathrm{~T}$ in the longer wavelength region, indicating that excitons are mainly generated in the polymer phase. The photovoltaic study of quinoxaline-based thiophene polymers shows it to be a promising donor material for $\mathrm{BHJ}$ solar cells.

\section{Conclusions}

In summary, we have synthesized new solution-processable quinoxaline-based low bandgap polymers using the Yamamoto and Stille coupling reactions. PQx6T showed good solubility in common organic solvents such as chloroform and chlorobenzene because of the long alkyl side chain, but PQx2T and $\mathrm{PQx} 4 \mathrm{~T}$ showed relatively poor solubility because of the rigid thiophene units in the polymer backbones. PQx2T, PQx4T, and PQx6T exhibited long wavelength UV-visible absorption peaks at 583,602 , and $608 \mathrm{~nm}$, respectively. A photovoltaic device using a PQx6T:PC ${ }_{71} \mathrm{BM}(1: 3)$ film as the active layer exhibited an open circuit voltage of $0.47 \mathrm{~V}$, a short circuit current density of $9.05 \mathrm{~mA} / \mathrm{cm}^{2}$, a fill factor of 0.42 , and a power conversion efficiency of $1.80 \%$ under AM $1.5 \mathrm{G}\left(100 \mathrm{~mW} / \mathrm{cm}^{2}\right)$ illumination.

Acknowledgments. This work was supported by a grant from the cooperative R\&D Program (B551179-08-03-00) funded by the Korea Research Council Industrial Science and Technology, Republic of Korea, and also supported by the Catholic University of Korea, Research Fund, 2010. This study was supported by a grant (M2009010025) from the Fundamental R\&D Program for Core Technology of Materials funded by the Ministry of Knowledge Economy (MKE), Republic of Korea.

\section{References}

1. Babel, A.; Jenekhe, S. A. Macromolecules 2003, 36, 7759.

2. Yoon, H.-S.; Lee, W.; Lee, J.-H.; Lim, D.-G.; Hwang, D-H.; Kang, I.-N. Bull. Korean Chem. Soc. 2009, 30, 2371.

3. Lee, W. H.; Kong, H.; Oh, S. Y.; Shim, H. K.; Kang, I. N. J. Polym. Sci. Part A: Polym. Chem. 2009, 47, 111.

4. Qin, Y.; Kim, J. Y.; Frisbie, C. D.; Hillmyer, M. A. Macromolecules 2008, 41, 5563.

5. Thompson, B. C.; Kim, B. J.; Kavulak, D. F.; Sivula, K.; Mauldin, C.; Fréchet J. M. J. Macromolecules 2007, 40, 7425.

6. Kim, Y.; Cook, S.; Tuladhar, S. M.; Choulis, S. A.; Nelson, J.; Durrant, J. R.; Bradley, D. D. C.; Giles, M.; McCulloch, I.; Ha, C.-S.; Ree, M. Nat. Mater. 2006, 5, 197.

7. Son, S. K.; Choi, Y. S.; Lee, W. H.; Hong, T.; Kim, J. R.; Shin, W. S.; Moon, S. J.; Hwang, D. H.; Kang, I. N. J. Polym. Sci. Part A: Polym. Chem. 2010, 48, 635.

8. Chen, H. Y.; Hou, J. H.; Zhang, S. Q.; Liang, Y. Y.; Yang, G. W.; Yang, Y.; Yu, L. P.; Wu, Y.; Li, G. Nat. Photon 2009, 3, 649.

9. Yu, G.; Gao, J.; Hummelen, J. C.; Wudl, F.; Heeger, A. J. Science 1995, 270, 1789.

10. Chen, J. W.; Cao, Y. Acc. Chem. Res. 2009, 42, 1709.

11. Li, Y. F.; Zou, Y. P. Adv. Mater. 2008, 20, 2952.

12. Thompson, B. C.; Fréchet, J. M. Angew. Chem. Int. Ed. 2008, 47, 58.

13. Chen, Y. J.; Yang, S. H.; Hsu, C. S. Chem. Rev. 2009, 109, 5868.

14. Wu, W. C.; Lee, W. Y.; Pai, C. L.; Chen, W. C.; Tuan, C. S.; Lin, 
J. L. J. Polym. Sci. Polym. Phys. 2007, 45, 67.

15. Tsai, J. H.; Chueh, C. C.; Lai, M. H.; Wang, C. F.; Chen, W. C.; Ko, B. T.; Ting, C. Macromolecules 2009, 42(6), 1897.

16. Chang, Y. T.; Hsu, S. L.; Chen, G. Y.; Su, M. H.; Singh, T. A.; Diau, W. G.; Wei, K. H. Adv. Funct. Mater. 2008, 18, 2356.

17. Inganas, O.; Zhang, F.; Tvingstedt, K.; Andersson, L. M. Hellstrom, S.; Andersson, M. R. Adv. Mater. 2010, 22, E100.

18. Lai, M. H.; Chueh, C. C.; Chen, W. C.; Wu, J. L.; Chen, F. C. J. Polym. Sci. Part A: Polym. Chem. 2009, 47, 973.

19. Gadisa, A.; Mammo, W.; Andersson, L. M.; Admassie, S.; Zhang, F.; Andersson, M. R.; Inganas, O. Adv. Funct. Mater. 2007, 17, 3836.

20. Peng, Q.; Zheng, Q. J. Polym. Sci. Part A: Polym. Chem. 2009, 47, 3399.

21. Lee, J. Y.; Shin, W. S.; Haw, J. R.; Moon, D. K. J. Mater. Chem. 2009, 19, 4938.

22. Yamamoto, T.; Zhou, Z. H.; Kanbara, T.; Shimura, M.; Kizu, K.; Maruyama, T.; Nakamura, Y.; Fukuda, T.; Lee, B. L.; Ooba, N.; Tomaru, S.; Kurihara, T.; Kaino, T.; Kubota, K.; Sasaki, S. J. Am.
Chem. Soc. 1996, 118, 10389.

23. Yang, R.; Tian, R.; Yan, J.; Zhang, Y.; Yang, J.; Hou, O.; Yang, W.; Zhang, C.; Cao, Y. Macromolecules 2005, 38, 244.

24. Tsubata, Y.; Suzuki, T.; Miyashi, T. J. Org. Chem. 1992, 57, 6749.

25. Ulrich, M. W. T.; Zhou, M. J. Org. Chem. 1994, 59, 4988.

26. Gray, G. W.; Hird, M.; Lacey, D.; Toyne, K. J. J. Chem. Soc. Perkin Trans. 1989, 2, 2041.

27. Tsami, A.; Yang, X.-H.; Farrell, T.; Neher, D.; Holder, E. J. Polym. Sci. Part A: Polym. Chem. 2008, 46, 7794.

28. Zhang, G.; Fu, Y.; Zhang, Q.; Xie, Z. Polymer 2010, 51, 2313.

29. Blouin, N.; Michaud, A.; Gendron, D.; Wakim, S.; Blair, E.; NeaguPlesu, R.; Belletete, M.; Durocher, G.; Tao, Y.; Leclerc, M. J. Am. Chem. Soc. 2008, 130, 732.

30. Yang, J.; Jiang, C. Y.; Zhang, Y.; Yang, R. Q.; Yang, W.; Hou, Q.; Cao, Y. Macromolecules 2004, 37, 1211.

31. Yang, R. Q.; Tian, R. Y.; Yan, J. G.; Zhang, Y.; Yang, J.; Hou, Q.; Yang, W.; Zhang, C.; Cao, Y. Macromolecules 2005, 38, 244.

32. Lee, J-Y.; Shin, W-S.; Haw, J-R.; Moon, D.-K. J. Mater. Chem. 2009, 19, 4938. 